\title{
Assessing The Reliability of Zygomatic Bone Landmarks as Guides to Reach The Inferior Orbital Fissure in Orbitozygomatic Osteotomy. Anatomical Study Of 83 Human Skulls.
}

\section{Semyon A Melchenko}

Burdenko National Medical Research Center of Neurosurgery

\section{Vasiliy A Cherekaev}

Burdenko National Medical Research Center of Neurosurgery

\section{Olga Yu Aleshkina}

Saratov State Medical University

\section{Gleb V Danilov}

Burdenko National Medical Research Center of Neurosurgery

Gerald Musa ( $\nabla$ gerryMD@outlook.com )

Rossijskij universitet druzby narodov https://orcid.org/0000-0001-8710-8652

Uliya V Strunina

Burdenko National Medical Research Center of Neurosurgery

Denis A Golbin

Burdenko National Medical Research Center of Neurosurgery

Nikolay V Lasunin

Burdenko National Medical Research Center of Neurosurgery

Alexander A Zaychenko

Saratov State Medical University

\section{Research Article}

Keywords: Orbitozygomatic, craniotomy, inferior orbital fissure, anatomic landmarks

Posted Date: September 24th, 2021

DOI: https://doi.org/10.21203/rs.3.rs-890328/v1

License: () (1) This work is licensed under a Creative Commons Attribution 4.0 International License. Read Full License 
Version of Record: A version of this preprint was published at Neurosurgical Review on January 13th, 2022. See the published version at https://doi.org/10.1007/s10143-021-01726-8. 


\section{Abstract}

\section{Objectives}

To perform an adequate orbito-zygomatic craniotomy, it is very important that the bone cut which passes through the body of the zygoma reaches the inferior orbital fissure (IOF). To reach the IOF, two surface landmarks on the body of the zygoma are described: a point located directly superior to the malar eminence and the zygomaticofacial foramen. The article explores the reliability of these landmarks and three other alternative points to reach the IOF.

\section{Method}

Eighty-three adult skulls were used in this study. The IOF dimensions and the relationship with the malar eminence, the point superior to the malar eminence, the zygomaticofacial foramen and 3 alternative points $(E, C, F)$ were analyzed.

\section{Results.}

The malar eminence was unacceptable for use as a guide to the IOF. The point superior to the malar eminence was also unacceptable as a guide as only $9.4 \%$ and $10.9 \%$ were in the projection of the IOF on the right and left, respectively. $59.7 \%$ of the total zygomaticofacial foramina fell in the IOF projection. The point $\mathrm{F}$ fell in the projection of the IOF in $98.8 \%$ and $100.0 \%$ on the right and left, respectively.

\section{Conclusion.}

The use of the malar eminence as a guide to reach the IOF is unreliable in one third of cases as it is not easily identified intraoperatively in these cases. The zygomaticofacial foramen cannot be considered a reliable surgical landmark to reach the IOF. The authors recommend using the point " $F$ " which is reliable in $98.8-100 \%$ of cases.

\section{Introduction}

The orbitozygomatic approach was proposed in 1984 [6]. It is used for a wide range of pathology, with a rather variable both intra-and extracranial localization. The orbitozygomatic craniotomy has been shown to offer the best angle of approach and working area compared to other craniotomies in this region [5]. It allows a surgeon access to the middle fossa, sellar region, the anterior fossa and the posterior fossa [11]. The advantages of the two-flap over the single flap orbitozygomatic craniotomy [12] are undoubted. Recent modification by Alvaro et al. includes a 3-piece approach [2]. The most commonly used version is the two-flap orbitozygomatic craniotomy, which was described in 1998. In an article by J.M. Zabramski, the author gives a detailed description of performing an orbitozygomatic bone flap [14]. For this method 6 bone cuts are performed (Fig. 1). 
According to Zabramski et al., one of the most difficult osteotomies is the third one, which begins on the body of the zygoma extending perpendicular to the inferolateral border of the orbit and then runs along the lateral wall of the orbit ending in the anterolateral edge of the inferior orbital fissure (IOF). The importance of this bone cut is mentioned in the anatomy works of C. Martins et al. [10]. In order to perform an orbitozygomatic craniotomy with as little retraction on the contents of the orbit as possible, the osteotomy should be extended to reach the IOF (Fig. 2). Zabramski et al. suggested that the starting point of the third bone cut should lie immediately above the malar eminence. From this point a line is drawn perpendicular to the inferolateral border of the orbit towards the IOF [14]. A number of authors also propose using the zygomaticofacial foramen as a guide. According to classical anatomy works, there are usually two zygomaticofacial foramina on each side through which the zygomaticofacial nerve and artery pass. The nerve is a branch of the zygomatic nerve, one of the terminal branches of the maxillary nerve (V2). Its zone of innervation overlaps with other branches of the trigeminal nerve, therefore sensory disorders do not occur when it is damaged $[10,7]$.

We did not find data in the literature on the possibility of using the above-mentioned landmarks depending on the width of the IOF. Also, there is no data on the distance from the inferior edge of the orbit to the anterolateral border of the IOF or the value of such landmarks as malar eminence and zygomaticofacial foramen in relation with each other and their variations.

\section{Objectives}

1. To examine the effectivity of the zygomaticofacial foramen and malar eminence when performing an adequate orbitozygomatic craniotomy

2. To introduce and examine 3 alternative points $E, C, F$ identified on the body of the zygoma when performing an orbitozygomatic craniotomy

\section{Materials And Methods}

The morphology of the orbitozygomatic complex was studied on 83 adult human skulls from the fundamental anatomic museum at the Department of Human Anatomy of Saratov State Medical University named after I. I. Razumovsky. All the skulls belonged to natives of Saratov and Saratov region who lived in this territory in the 20th century. The main inclusion criteria in the study were preservation of bone structures and unaltered skull anatomy. Measurements were made using nearly $0.01 \mathrm{~mm}$ scale spreading calipers according to the conventional methods of craniology. All skulls were divided according to age, sex, skull shape and basilar angle type. The anterolateral IOF margin width (Fig. 3a) and the distance from the anterolateral point of the IOF along the inferolateral edge of the orbit extending to the inferior margin of the orbit was measured (Fig. 3b).

Other variables included: presence and prominence of the malar eminence, number of zygomaticofacial foramina, their diameter, and the distance between each zygomaticofacial foramen and the inferior margin of the orbit. The projection of the anterolateral margin of the IOF on the body of the zygoma is the 
zone located between the two vectors. The first one begins from the superior edge of the anterolateral edge of the IOF, continues vertical to the inferolateral edge of the orbit and crossing the body of the zygoma. The second line begins from the inferior edge of the anterolateral part of the IOF and continues vertical to the inferolateral edge of the orbit, and then crosses the body of the zygoma (Fig. 3c). The possibility of finding the malar eminence and zygomaticofacial foramina in the area of IOF projection on the body of the zygoma was assessed (Fig. 3d).

The use of three alternative points - E, C, F (identified on the body of the zygoma when performing the orbitozygomatic craniotomy) to reach the IOF was examined. A line was drawn across EC on the body of the zygoma. The EC segment is drawn on a line marked " $b$ " an extension of a line from the lower edge of the zygomatic process onto the body of the zygoma. This line runs parallel to the other line "a" which extends from the superior edge of the zygomatic process. From point $B$, located on the elevation of the lateral edge of the frontal process of the zygoma, a vertical line is drawn to intersect the line "b" at point $C$ i.e., line $\mathrm{BC}$. Another line perpendicular to line "b" is drawn from point $\mathrm{D}$ which is the point located on the medial edge of the frontal process of the zygoma, to the point $E$ on the body of the zygoma i.e., line "DE". A midpoint between $\mathrm{E}$ and $\mathrm{C}$ is marked point $\mathrm{F}$ (Fig. 4).

\section{Results}

The distance from the lateral point of the IOF to the lateral edge of the orbit was $16.2 \pm 2.1 \mathrm{~mm}$ (median $16 \mathrm{~mm}$, range of $11-22 \mathrm{~mm}$ ), and $16.1 \pm 2.1 \mathrm{~mm}$ (median $16 \mathrm{~mm}$, range of $11-21 \mathrm{~mm}$ ) on the right and left respectively. The width of the IOF on the right side was $5.2 \pm 2.4 \mathrm{~mm}$ (median $5 \mathrm{~mm}$, range 2-18 mm), and on the left side $5.1 \pm 2.6 \mathrm{~mm}$ (median $4 \mathrm{~mm}$, range 2-19 mm) (Fig. 5).

We evaluated malar eminence for its use as a guide to the third bone cut. If the malar eminence was easy to identify on the body of the zygoma and no difficulties arose when identifying the place of the third bone cut, then such an eminence was labeled an acceptable landmark. Conversely, an absent, barely palpable or very wide eminence was considered unacceptable (Fig. 6). The malar eminence was an unacceptable landmark in $36,1 \%(\mathrm{~N}=30)$ on the right side and $33,7 \%(\mathrm{~N}=28)$ on the left side. In cases with acceptable malar eminence, the point located immediately superior to it did not fall into the projection of the IOF on the right side in $9.4 \%(\mathrm{~N}=5)$ and in $10.9 \%(\mathrm{~N}=6)$ on the left side (Fig. 7). The number of zygomaticofacial foramina ranged from 0 to 4 small foramina. One foramen was present on the right in $42,2 \%(N=35)$ and $44,6 \%(N=37)$ on the left. Two foramina were found in $37.3 \%(N=31)$ on the right side and in $36.1 \%(\mathrm{~N}=30)$ on the left side, three foramina on the right - in $12.0 \% \mathrm{~N}=10$ and on the left - in $8.4 \%(N=7)$, and four foramina on the right in $3.6 \%(N=3)$ and on the left in $4.8 \%(N=4)$. The zygomaticofacial foramen was not visualized on the right in $4,8 \%(N=4)$ and on the left - in $6,0 \%(N=5)$.

For skulls with one zygomaticofacial foramen, its average diameter was $1.7 \pm 0.8 \mathrm{~mm}$ (median $2 \mathrm{~mm}$, range $0.2-3 \mathrm{~mm}$ ) on the right and $1.9 \pm 0.8 \mathrm{~mm}$ (median $2 \mathrm{~mm}$, range $0.2-3.5 \mathrm{~mm}$ ) on the left. In cases with two zygomaticofacial foramina on the right, the average diameter of the upper foramina was $1.8 \pm$ $0.5 \mathrm{~mm}$ (median $2 \mathrm{~mm}$, range 1-3.5 mm) and the lower - $1.6 \pm 0.6 \mathrm{~mm}$ (median $2 \mathrm{~mm}$, range 0.3-3mm), 
and on the left the average diameter of the upper foramina was $1.5 \pm 0.6 \mathrm{~mm}$ (median $1.5 \mathrm{~mm}$, range 0.5$3 \mathrm{~mm}$ ) and the lower foramina $1.5 \pm 0.7 \mathrm{~mm}$ (media $1.5 \mathrm{~mm}$, range $0.2-3 \mathrm{~mm}$ ). In cases with three foramina on the right, the average diameter of the upper foramina was $1.7 \pm 1.6 \mathrm{~mm}$ (media $1.25 \mathrm{~mm}$, range 0.3-6 $\mathrm{mm}$ ), middle foramina $1.3 \pm 0.7 \mathrm{~mm}$ (median $1.25 \mathrm{~mm}$, range $0.3-2.5 \mathrm{~mm}$ ), lower foramina $1.1 \pm 0.7 \mathrm{~mm}$ (median $1 \mathrm{~mm}$, range 0.3-2 $\mathrm{mm}$ ), and on the left, the upper foramina was $1.4 \pm 0.8 \mathrm{~mm}$ (median $1 \mathrm{~mm}$, range $0.3-2.5 \mathrm{~mm}$ ), middle foramina $0.8 \pm 0.5 \mathrm{~mm}$ (median $0.5 \mathrm{~mm}$, range $0.3-1.5 \mathrm{~mm}$ ), the lower foramina $1.1 \pm 0.9 \mathrm{~mm}$ (median $1 \mathrm{~mm}$, range $0.3-3 \mathrm{~mm}$ ). In case of four foramina on the right, the average diameter of the upper foramina was $2.2 \pm 0.3 \mathrm{~mm}$ (median $2 \mathrm{~mm}$, range 2-2.5 $\mathrm{mm}$ ), the middle upper foramina $1 \pm 0 \mathrm{~mm}$, the middle upper foramina $1.6 \pm 0.7 \mathrm{~mm}$ (median $2 \mathrm{~mm}$, range 0.8 $2 \mathrm{~mm}$ ) and the lower foramina $1.3 \pm 1.1 \mathrm{~mm}$ (median $0.8 \mathrm{~mm}$, range $0.5-2.5 \mathrm{~mm}$ ) distribution. On the left the average diameter of the upper foramina was $1.8 \pm 0.5 \mathrm{~mm}$ (median $2 \mathrm{~mm}$, range 1-2 mm), the middle upper foramina $1.3 \pm 1.2 \mathrm{~mm}$ (median $0.85 \mathrm{~mm}$, range $0.5-3 \mathrm{~mm}$ ), the middle lower foramina $1.3 \pm 0.7$ $\mathrm{mm}$ (median $1.5 \mathrm{~mm}$, range 0.3-2 $\mathrm{mm}$ ) and the lower foramina $0.7 \pm 0.4 \mathrm{~mm}$ (median $0.75 \mathrm{~mm}$, range 0.3$1 \mathrm{~mm}$ ). There was no statistically significant difference in the size of the foramina.

Of the total number of zygomaticofacial foramina $(N=273$, right -139 , left -134$) 59.7 \%(N=163$, right 83 , left -80 ) were in the projection of the IOF. In cases with one foramen, it was in the projection of the IOF on the right in $60 \%$ and on the left in $56.8 \%$ of cases. With two foramina, the lower foramen commonly falls in the projection of the IOF. On the right, the upper and lower foramen were in the IOF projection in $29 \%$ and $87.1 \%$, respectively, and on the left - in $36.7 \%$ and $83.3 \%$, respectively. With three zygomaticofacial foramina, we did not find statistically significant results considering the location of the foramina in the projection of the IOF. On the right, the upper, middle and lower foramina were in the projection of the IOF in $20 \%, 60 \%$ and $70 \%$, respectively and in $28.6 \%, 71.4 \%$ and $28.6 \%$ on the left respectively. With four zygomaticofacial foramina, we did not find statistically significant results considering location of the foramina in the projection of the IOF. The upper, upper-middle, lower-middle and lower foramina were in the projection of the IOF in $33.3 \%, 100 \%, 100 \%$, and $66.7 \%$ on the right, respectively and in $25 \%, 75 \%, 100 \%$ and $50 \%$ on the left, respectively (Fig. 8).

For the proposed alternative landmarks $\mathrm{E}, \mathrm{F}$ and $\mathrm{C}$, the probability of correspondence with the IOF projection was calculated. The point $E$ fell within the projection of the IOF in $52.4 \%(\mathrm{~N}=45)$ on the right and in $49.3 \%(N=41)$ - on the left; the point $C$ in $73.4 \%(N=61)$ on the right and in $68.6 \%(N=57)$ on the left; the point $\mathrm{F}$ - in $98.8 \%(\mathrm{~N}=82)$ on the right and in $100 \%(\mathrm{~N}=83)$ on the left. There was a direct relationship between points $\mathrm{E}$ and $\mathrm{C}$ and the width of the IOF. The wider the IOF is, the more likely is that points $E$ and $C$ will fall in the projection of the IOF $(p<0.005)$

\section{Discussion}

When performing orbito-zygomatic craniotomy, a surgeon is not always able to identify the lateral edge of the IOF. This is due to the fact that good exposure of the IOF requires traction of the contents of the orbit which can lead to damage to these structures and can induce an orbito-cardiac parasympathetic reflex which may cause bradycardia and asystole [13]. In addition, this requires considerable traction on the 
myofascial flap which can damage the frontal branch of the facial nerve $[3,8]$. The average distance from the orbital edge to the lateral point of the IOF is $16 \mathrm{~mm}$, ranging from a minimum of $11 \mathrm{~mm}$ to a maximum of $22 \mathrm{~mm}$. This knowledge allows a surgeon to plan the depth of osteotomy using surgical instruments with a minimal risk of damage to the structures of the IOF.

According to literature review, natural landmarks on the body of the zygoma that have been used to perform an osteotomy in the direction of IOF include malar eminence and the zygomaticofacial foramen. However, to be considered a reliable surgical landmark, the anatomical structure must be easily identifiable and relatively constant [10]. But according to our data, the malar eminence in $1 / 3$ of cases is difficult to identify (33.7-36.1\%). In some cases where the eminence was easily palpable, the point located directly superior to it did not fall in the projection of the IOF (9.4-10.9\%). The zygomaticofacial foramina were absent on the body of the zygoma in some cases (4.8-6.0\%). In our findings one zygomaticofacial foramen was seen in slightly less than half of the skulls (42-44.6\%) and two foramina were seen in one third of cases (36.1-37.3\%), three foramina in $8,4-12,0 \%$ and four foramina in 3,6 $4,8 \%$. In cases with one zygomaticofacial foramen, it was a reliable guide in $56.8-60 \%$. And when two zygomaticofacial foramina were identified, the reliable guide was the lower foramen as it fell in the projection of the IOF in $83.3-87.1 \%$, while the upper foramen was only reliable in $29-36.7 \%$. When three and four foramina were identified, reliability as a landmark ranged from $20-100 \%$. This result was not statistically significant because very few cases with more than 2 foramina were seen. Whether or not the zygomaticofacial foramen falls in the projection of the IOF is not dependent on its diameter. The use of the zygomaticofacial foramen as a landmark to reach the IOF is controversial and impractical, given the low probability to reach the IOF. Many authors have found this landmark unreliable, considering variability of positions, the number of foramina and their frequent absence $[10,1,4,9]$. This is in agreement with the above results.

The use of the malar eminence as a surgical landmark increases the probability of reaching the IOF during surgery. However, in about one third of patients the protuberance is difficult to identify intraoperatively, making it unreliable as a landmark for orbitozygomatic craniotomy. The greater the width of the IOF, the more likely a surgeon will get into the projection of the IOF when performing the craniotomy. Hence, the need for a cautious CT analysis preoperatively cannot be overemphasized.

The use of point $F$ that we have proposed, allows the surgeon to reach the IOF in $98.8-100 \%$. This point is calculated individually on each side and is directly dependent on the anatomic structure of the orbitozygomatic complex. It is easily identified intraoperatively. As far as we know, this is the first description of this point.

The major limitation of our research was a relatively small sample size - 83 human skulls. It may have reduced the significance of our results. In the future, including skulls from different geographical regions and different races would help to increase the sample size and reduce the selection bias.

\section{Conclusions}


Any surgeon planning to perform an orbitozygomatic craniotomy should be well aware of the anatomical structure of the orbitozygomatic complex. During preoperative planning, it is important to pay attention to the width of the IOF on skull CT. In most cases, it is enough to drive the bone saw to a depth of about 16 $\mathrm{mm}$ in order to reach the IOF. The use of the malar eminence as a landmark to reach the IOF is unreliable in one third of cases, as it is difficult to identify intraoperatively. The zygomaticofacial foramen, in our opinion, cannot be considered a reliable surgical landmark to reach the IOF due to its high anatomic variability and low probability of reaching the IOF (13\% to $75 \%$, on average $40 \%)$. The authors propose using point $F$ which is easy to locate intraoperatively and which has the highest probability of reaching the IOF (98.8-100\%).

\section{Abbreviations}

IOF inferior orbital fissure

\section{Declarations}

Funding No funds, grants, or other support was received.

Conflicts of interest/Competing interests Not applicable

Availability of data and material Not applicable

Code availability Not applicable

\section{Authors' contributions}

Semyon A. Melchenko: Conceptualization, methodology, Writing - Review \& Editing, Supervision

Vasiliy A. Cherekaev: Conceptualization, Writing - Review \& Editing, Supervision

Olga Yu. Alyoshkina: Writing - Review \& Editing, Formal analysis

Gleb V. Danilov: Writing - Review \& Editing, Resources

Musa Gerald: Writing - Original Draft, Resources, Writing - Review \& Editing,

Uliya V. Strunina: Writing - Original Draft, Supervision, Data curation

Denis A. Golbin: Writing - Original Draft, Formal analysis, Visualization

Nikolay V. Lasunin: Writing - Review \& Editing, Data curation

Alexander A. Zaychenko: Writing - Review \& Editing, Methodology 
Ethics approval The Saratov State Medical University named after I. I. Razumovsky Research Ethics Committee has confirmed that no ethical approval is required.

Consent to participate Not applicable

Consent for publication Not applicable

\section{References}

1. Aksu F, Ceri NG, Arman C, Zeybek FG, Tetik S (2009) Location and incidence of the zygomaticofacial foramen: An anatomic study. Clinical Anatomy: The Official Journal of the American Association of Clinical Anatomists the British Association of Clinical Anatomists 22:559-562

2. Campero A, Martins C, Socolovsky M, Torino R, Yasuda A, Domitrovic L, Rhoton A Jr (2010) Threepiece orbitozygomatic approach. Operative Neurosurgery 66:ons-E119-ons-E120

3. Cohen-Gadol A (2020) The orbitozygomatic craniotomy and its judicious use. Operative Neurosurgery 18:559-569

4. Ferro A, Basyuni S, Brassett C, Santhanam V (2017) Study of anatomical variations of the zygomaticofacial foramen and calculation of reliable reference points for operation. $\mathrm{Br} \mathrm{J}$ Oral Maxillofac Surg 55:1035-1041

5. Gonzalez LF, Crawford NR, Horgan MA, Deshmukh P, Zabramski JM, Spetzler RF (2002) Working area and angle of attack in three cranial base approaches: pterional, orbitozygomatic, and maxillary extension of the orbitozygomatic approach. Neurosurgery 50:550-557

6. Hakuba A, Liu S, Nishimura S (1986) The orbitozygomatic infratemporal approach: a new surgical technique. Surg Neurol 26:271-276. doi:10.1016/0090-3019(86)90161-8

7. Kodera T, Arishima H, Yamada S, Arai H, Akazawa A, Higashino Y, Kitai R, lino S, Bertalanffy H, Kikuta K-i (2017) Orbitozygomatic craniotomy with modified zabramski's technique: a technical note and anatomic and clinical findings. World neurosurgery 97:49-57

8. Lemole GM, Henn JS, Zabramski JM, Spetzler RF (2003) Modifications to the orbitozygomatic approach. Journal of neurosurgery 99:924-930

9. Lone M, Telang A, Rajgopal L, Bhuiyan PS (2016) Location and incidence of the zygomatico-facial foramen in dry human skulls: An anatomical study. Journal of the Anatomical Society of India 65:164-166

10. Martins C, Li X, Rhoton AL Jr (2003) Role of the zygomaticofacial foramen in the orbitozygomatic craniotomy: anatomic report. Neurosurgery 53:168-172. doi:10.1227/01.neu.0000068841.17293.bb discussion 172 - 163.

11. Ruzevick J, Raza SM, Recinos PF, Chaichana K, Pradilla G, Kim JE, Olivi A, Weingart J, Evans J, Quinones-Hinojosa A (2015) Orbitozygomatic craniotomy using an ultrasonic osteotome for precise osteotomies. Clinical neurology neurosurgery 134:24-27 
12. Tanriover N, Ulm AJ, Rhoton AL Jr, Kawashima M, Yoshioka N, Lewis SB (2006) One-piece versus two-piece orbitozygomatic craniotomy: quantitative and qualitative considerations. Neurosurgery 58:ONS-229-237; discussion ONS-237. doi:10.1227/01.Neu.0000210010.46680.B4

13. van Furth WR, Agur AMR, Woolridge N, Cusimano MD (2006) The orbitozygomatic approach. Neurosurgery 58:ONS-103-ONS-107

14. Zabramski JM, Kiriş T, Sankhla SK, Cabiol J, Spetzler RF (1998) Orbitozygomatic craniotomy. Technical note. J Neurosurg 89:336-341. doi:10.3171/jns.1998.89.2.0336

\section{Figures}
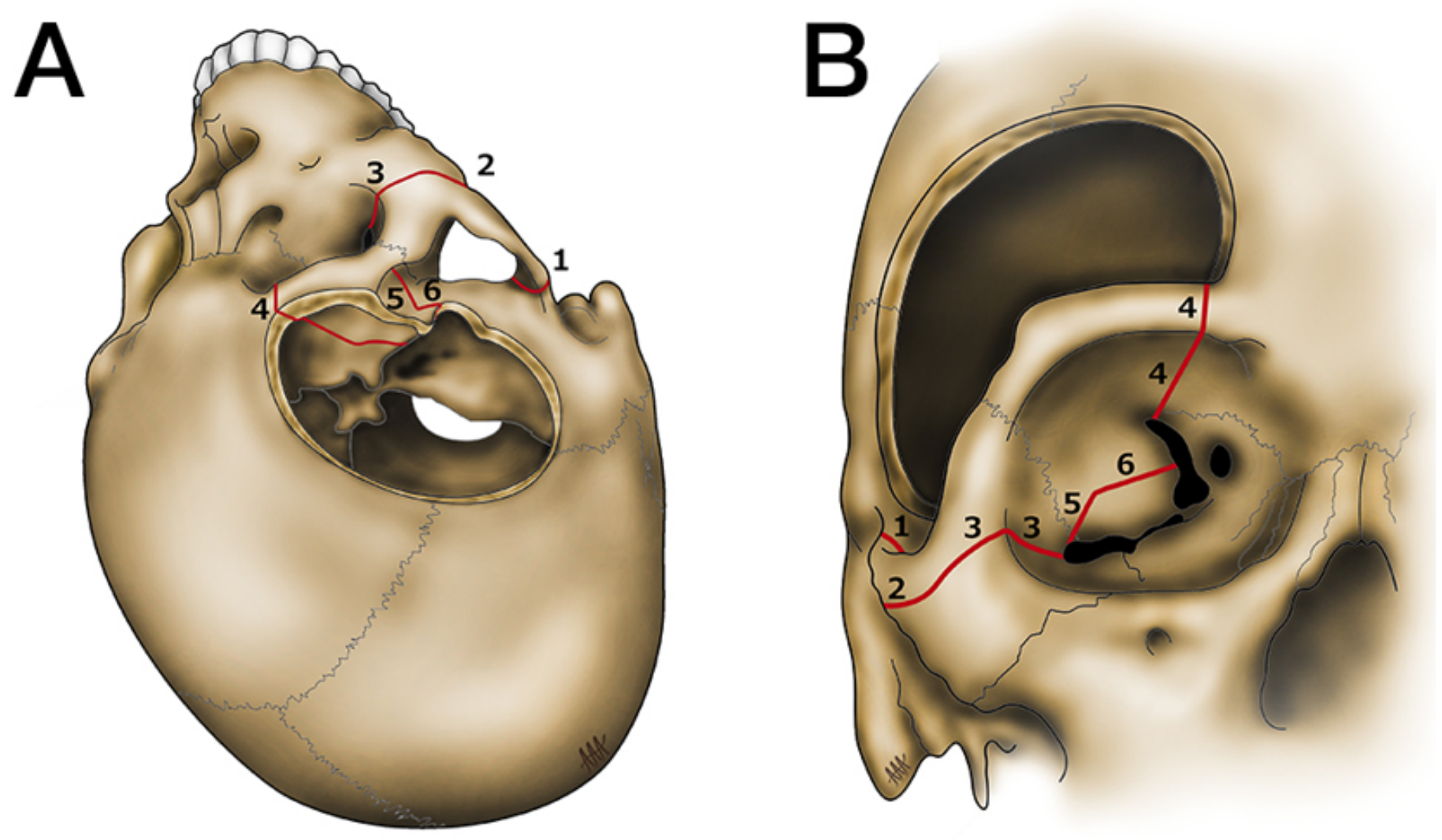

Figure 1

Location of six the 6 bone cuts used to form an orbitozygomatic craniotomy. The figures indicate the order of placement of the cuts; $\mathrm{a}$ - Lateral view; $\mathrm{b}$ - Anterior view 


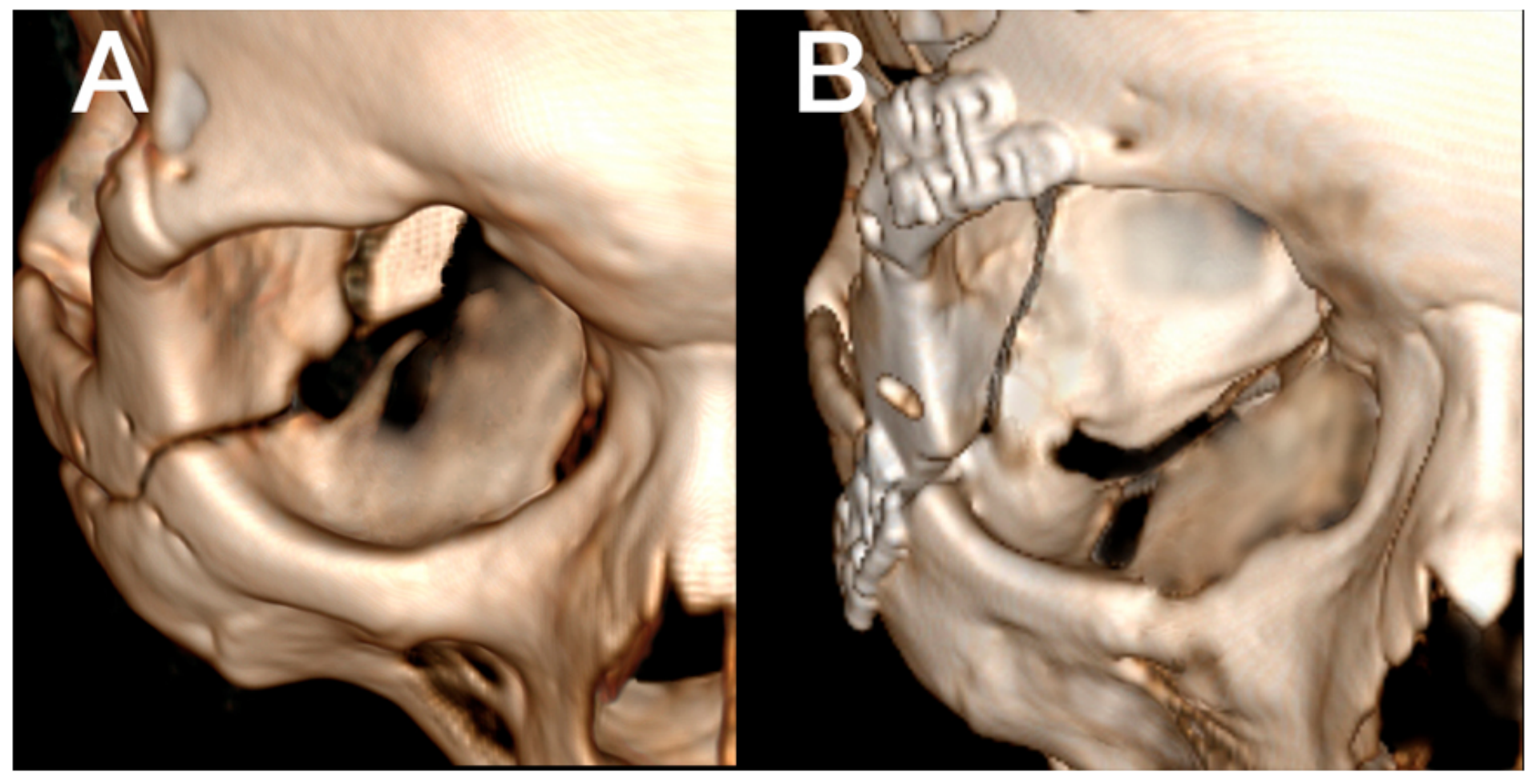

Figure 2

A skull 3D CT reconstruction with emphasis on the third bone section when performing an orbitozygomatic craniotomy. a - correct bone section, $b$ - incorrect bone section 

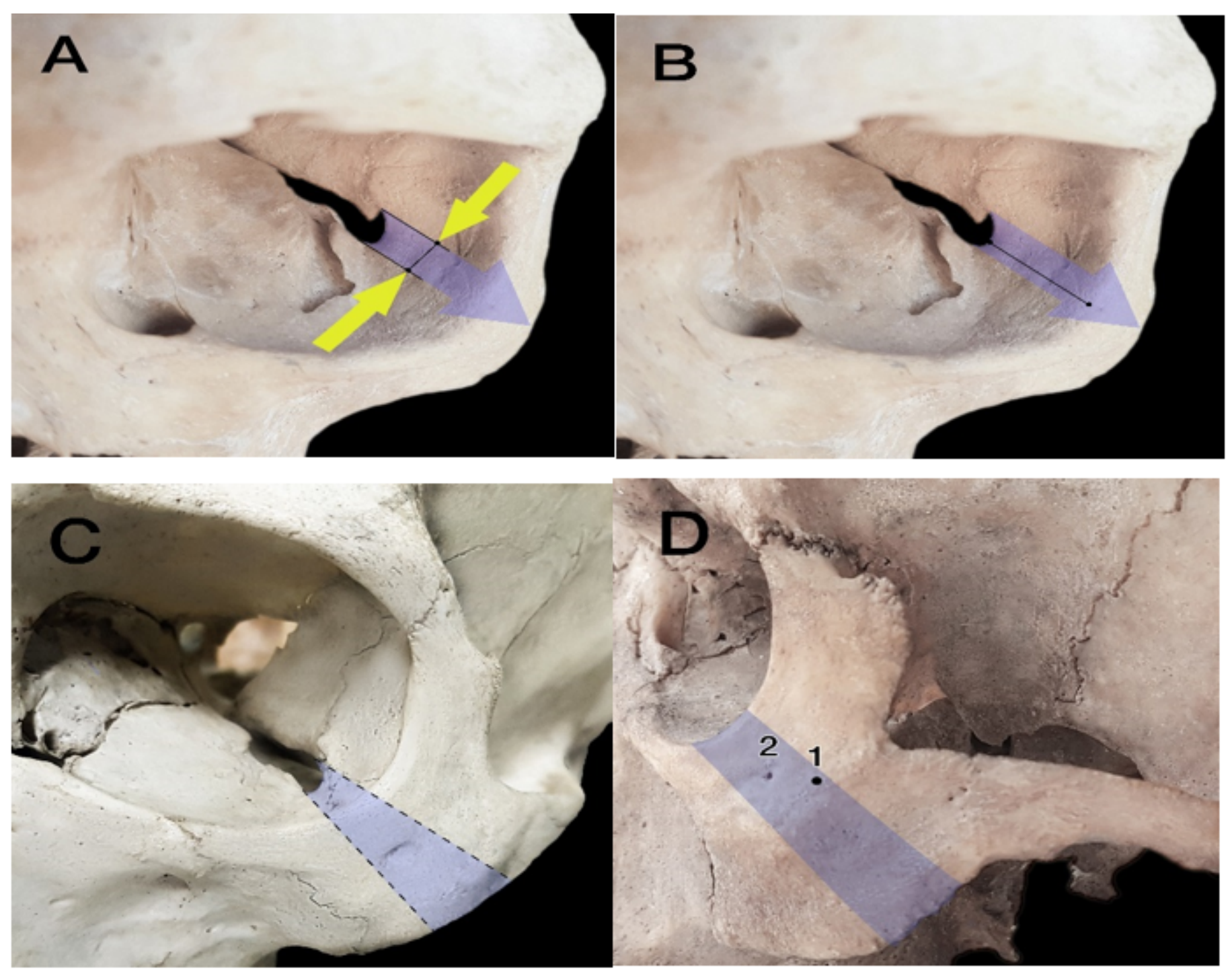

Figure 3

a- The width of the inferior orbital fissure, b- Distance from the anterolateral point of the inferior orbital fissure to the inferolateral edge of the orbit on the axis of the IOF. c- Projection of the anterolateral edge of the IOF on the body of the zygoma. $d$-Natural landmarks found on the body of the zygoma; 1 - a point above the malar eminence, 2 - Zygomaticofacial foramen 


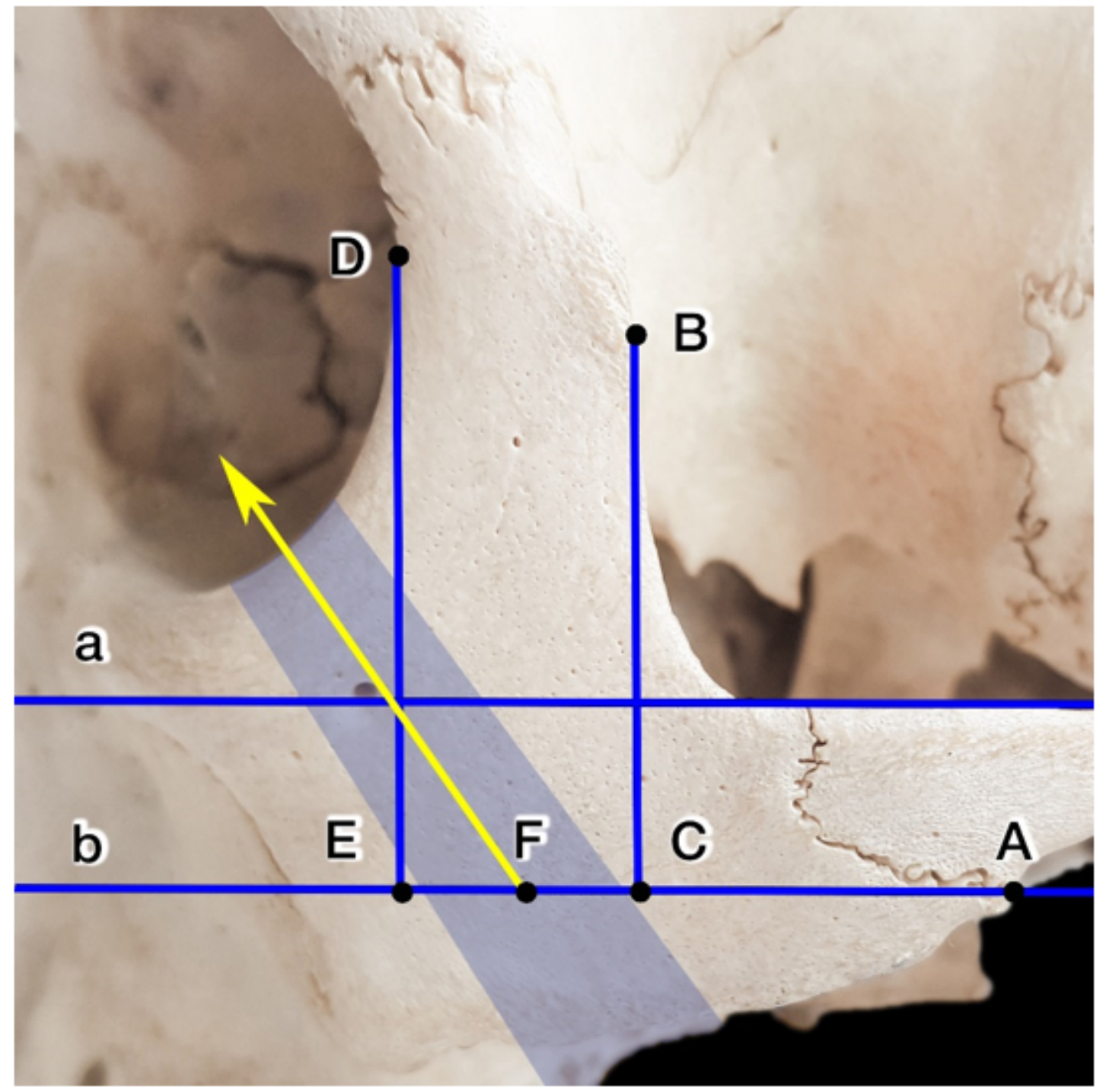

Figure 4

Points $E, C$ and $F$ on the body of the zygoma
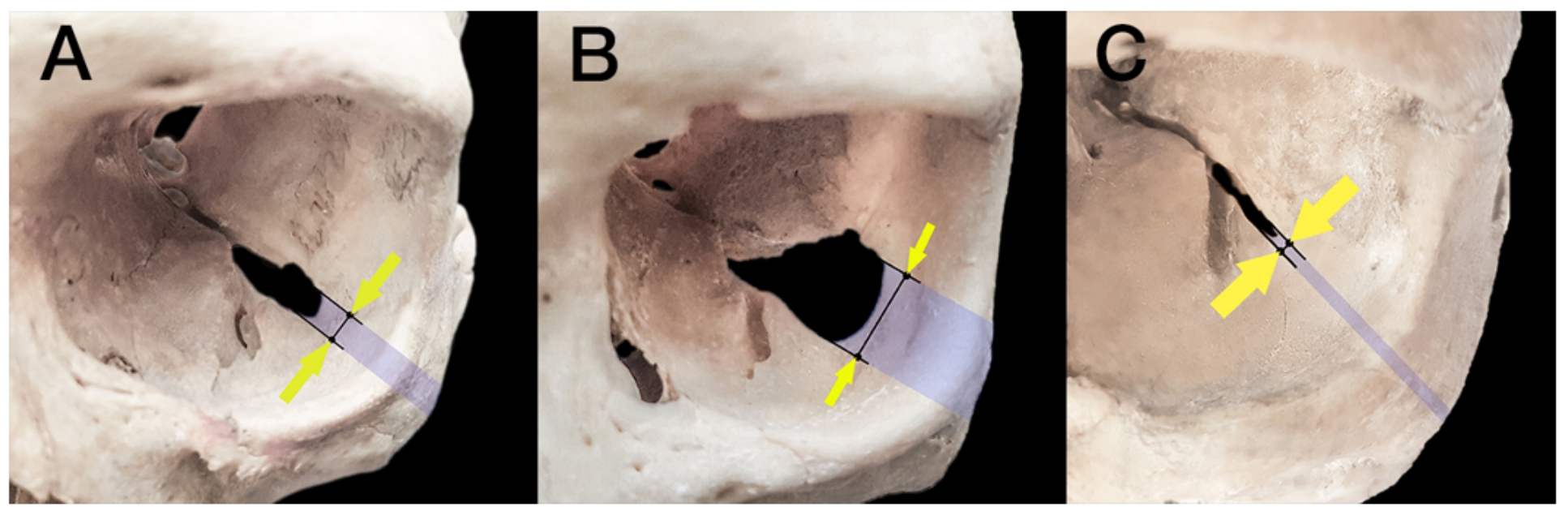

Figure 5 
Variations for the width of the IOF; moderate, very wide and narrow

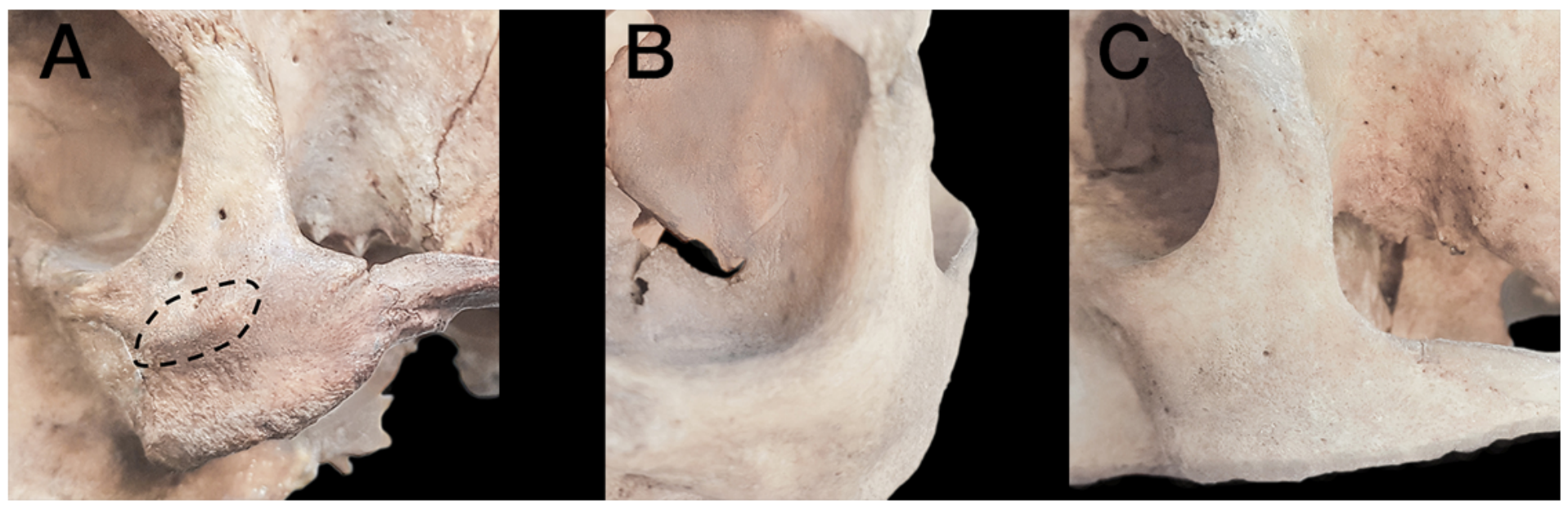

Figure 6

Variations of the malar eminence: a-Eminence on the body of the Zygoma; $b$ - Eminence is not identified anterior view, c- Eminence not identified lateral view

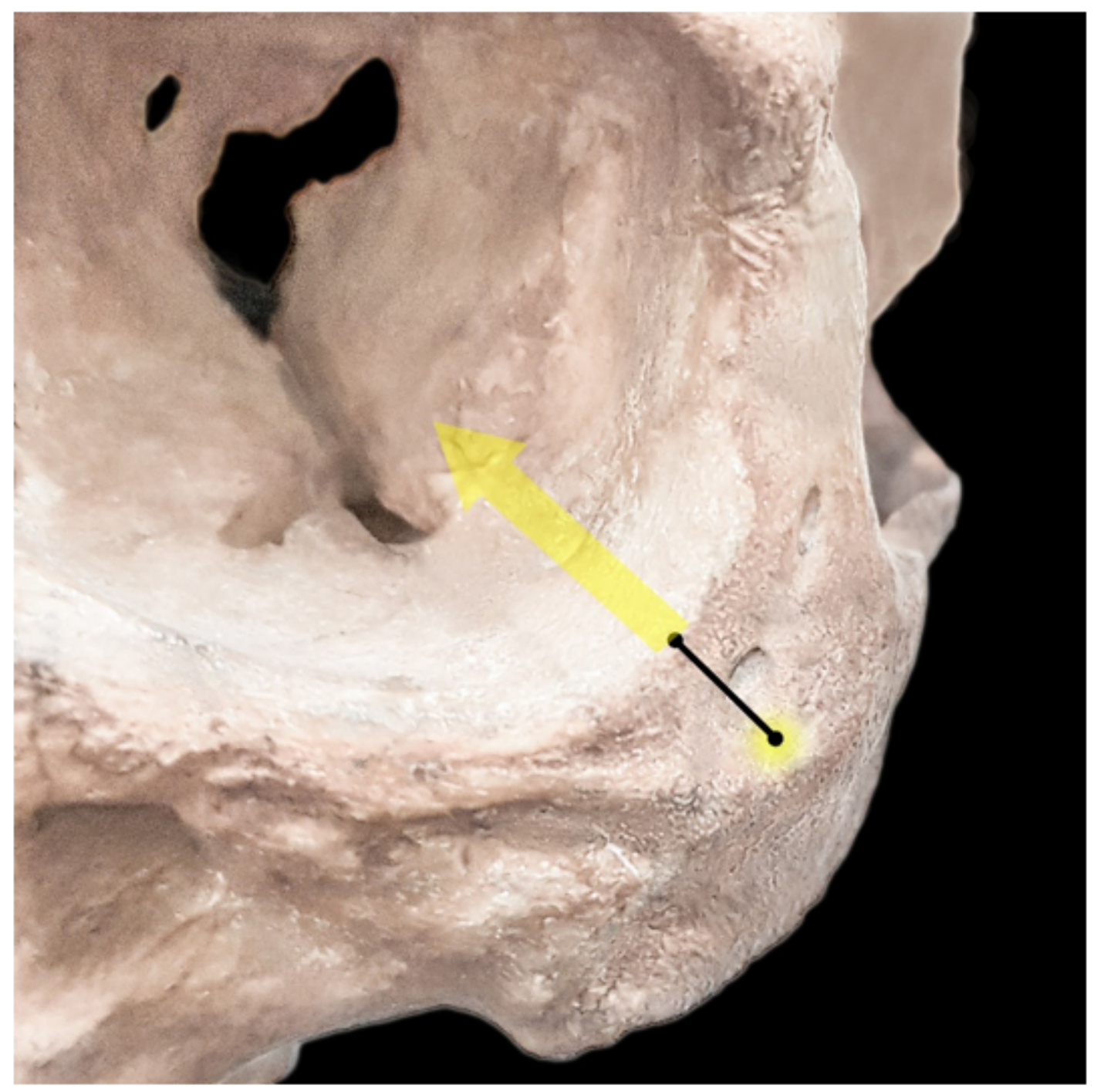

Figure 7 
The point above the malar eminence does not fall into the IOF projection
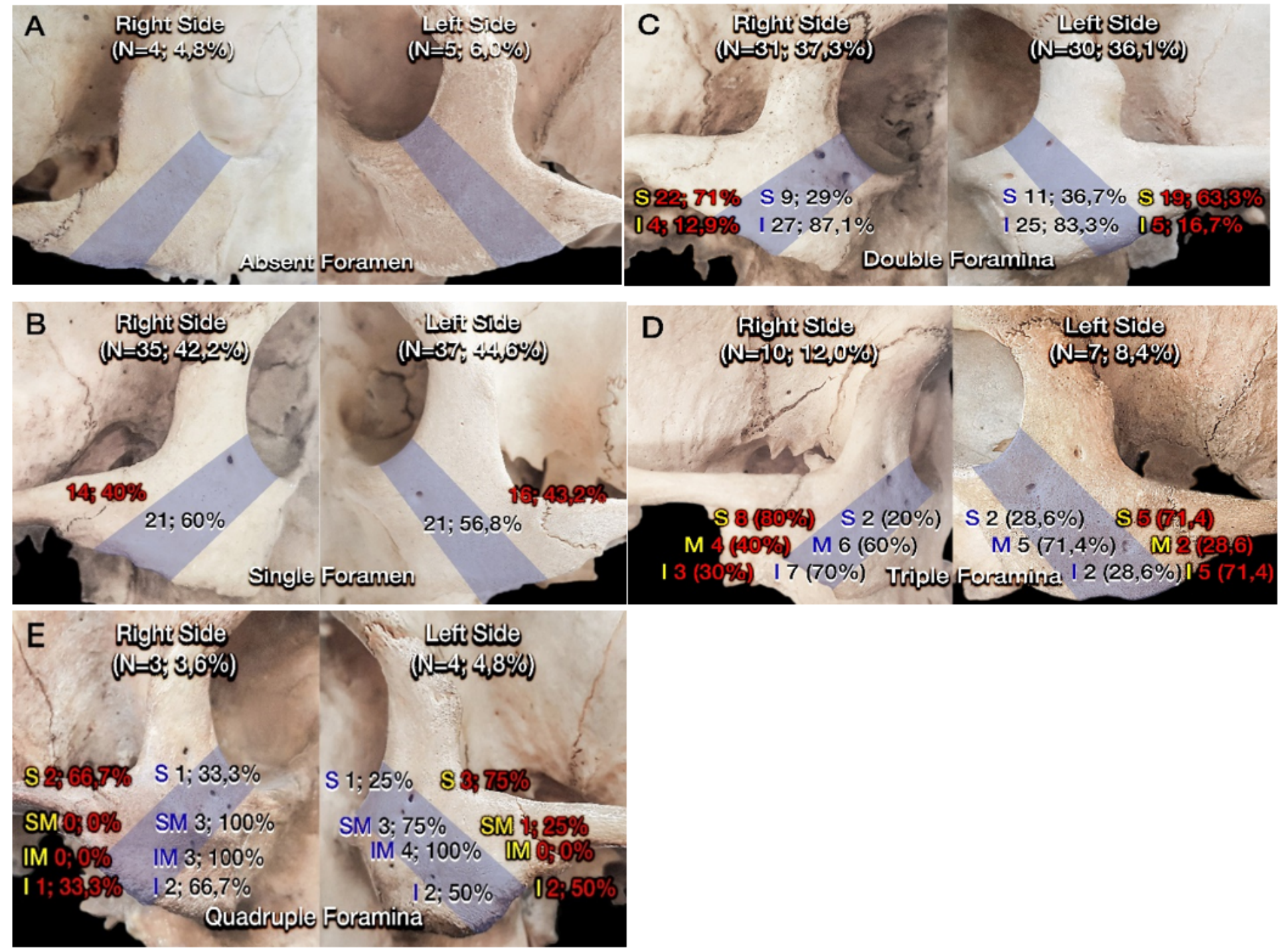

\section{Figure 8}

The relationship between the zygomaticofacial foramen and the IOF. On the zygoma the number of foramina located inside (black digits) and outside (red digits) of the IOF projection are indicated

\section{Supplementary Files}

This is a list of supplementary files associated with this preprint. Click to download.

- ACTAChecklistforauthors161027.doc 